\title{
Tradición e inestabilidad en la crítica argentina sobre el Quijote
}

Nora González y Germán Prósperi

Universidad Nacional del Litoral

\section{Resumen}

En este trabajo abordamos la manera en que algunos textos críticos de novelistas argentinos se inscriben en la tradición del cervantismo nacional. Muchas de sus intervenciones críticas postulan que el Quijote es metáfora de lectura, pero al mismo tiempo colocan $s u$ lectura en un punto inestable que no alcanzan a definir. Este espacio puede caracterizarse como la referencia a cuestiones que proyectan el texto cervantino hacia categorías propias de la didáctica o de los modos en que una lectura también puede enseñar o ser enseñada. De este modo la crítica entra en diálogo con una dimensión que el hispanismo argentino tardó en advertir pero que tenía en la obra de autores españoles una presencia reconocible.

1.

En un texto poco conocido, Juan José Saer (1999) plantea cierta incomodidad en relación con la crítica acerca del Quijote, sobre la que dice que está prioritariamente orientada a buscar sentidos ocultos en el texto, práctica que él condena por considerar que Cervantes escribió un texto plagado de evidencias, las que no pueden agostarse en infinitas lecturas. Ante la crítica preocupada por ver lo oculto, Saer propone rastrear las pistas que claramente invaden la escritura sin opacar la interpretación.

Este protocolo que la crítica de Saer propone puede reconstruirse si pensamos en algunos de los modos en que la crítica argentina se ha referido al texto de Cervantes, operación que encuentran su antecedente en algunos modelos peninsulares. Una difícil reconstrucción del cervantismo en Argentina puede reconocer nombres y modalidades de lectura diversos de lo que Juan Diego Vila denomina "una pasión nacional" ${ }^{1}$. Más allá de diferencias y modulaciones, es posible advertir una tradición iniciada a principios del s. XX a través de la escuela filológica española y que todavía encuentra proyecciones en los recorridos teóricos de numerosos investigadores nacionales. Proyectos de investigación, tesis doctorales, cursos de posgrado, cuya enumeración excede el carácter de este escrito, dan cuenta de la vigencia de un texto que permite delinear los modos de producir conocimiento en el ámbito del 
hispanismo nacional y trazar los alcances políticos de las elecciones que la crítica realiza en sus recorridos. Como sostiene Juan Diego Vila:

Leer el Quijote, trabajar críticamente con esta obra, fueron actividades que, durante muchos años, se sintieron propias de un colectivo intelectual harto difuso, el de los hispanistas. Conjunto de voluntades que, con claridad, trazaba de continuo de uno a otro lado del Atlántico los vínculos, continuidades y rupturas entre lo que fue la metrópoli y sus colonias, núcleo intelectual que también, justo es reconocerlo, intentó el prodigio de superar determinismos nacionales y edificar, paso a paso, una historia crítica que no por centrarse en un objeto de estudio foráneo debería ser percibida como menos propia. (Vila, 2005, p.16)

Es nuestra intención indagar en la manera en que en esa historia crítica se inscriben los trabajos de algunos productores de ficción que también son reconocidos en el campo de la crítica. Muchas de sus intervenciones críticas postulan que el Quijote es metáfora de lectura, pero al mismo tiempo colocan su lectura en un punto inestable que no alcanzan a definir. Este espacio puede caracterizarse como la referencia a cuestiones que proyectan el texto cervantino hacia categorías propias de la didáctica o de los modos en que una lectura también puede enseñar o ser enseñada. De este modo la crítica entra en diálogo con una dimensión que el hispanismo argentino tardó en reconocer pero que tenía en la obra de autores españoles una presencia constatable. Es en algunos textos de Juan Goytisolo en los que advertimos estas proyecciones que la propia voz autoral se empeña en silenciar.

\section{Goytisolo o el contagio conmovedor}

Juan Goytisolo se ha referido en numerosas oportunidades al Quijote. En 1991, postula a la escritura de Cervantes como una contrateoría de las poéticas de la novela, las que según Goytisolo no pueden existir. En relación con Cervantes, escribe:

Su aventura novelesca, calificada por él de proeza y rara invención no cabía en escuelas ni archivos de modelos. Como pregunta con razón Américo Castro, ‘¿Hubiera podido el autor del Quijote componer un Arte Nuevo de hacer comedias?' A todas luces, no. Porque sencillamente no hay talleres poéticos ni novelescos ni de obras literarias de alta calidad pese a su proliferación lucrativa conforme al ejemplo de las universidades norteamericanas. La creación nace, al contrario, a partir de una rebeldía: el proceso incoado por el escritor a las reglas del juego. (Goytisolo, 1991[1995], p. 250)

Si la novela de Cervantes es rebeldía, Goytisolo expone su propia poética de la escritura novelística y ensayística en esta serie en la que Cervantes es también, como él, un disidente. Novela sin teoría, género sin poética, escritura sin protocolo. Sólo la lectura como encadenamiento y la escritura como continuación. En esta argumentación, el Quijote ocupa el lugar de un buen texto sólo por el hecho de que permite ser releído, condición única de la excepcionalidad a la que la novela debe apuntar. En esta misma línea se encuentra la tesis de Milan Kundera (1987), quien se pregunta acerca del estatuto de la figura del escritor en tanto continuador de Cervantes. Kundera se refiere al futuro de la novela europea y advierte acerca de una serie que denomina "la desprestigiada herencia de Cervantes", serie de la que él se excluye en tanto figura de autor que se reconoce en la herencia cervantina, recompensa que extraña aún más cuando pensamos que Kundera escribe en una lengua que no es la del Quijote.

Goytisolo trabaja también con la representación del escritor como relector, figura altamente selectiva de los materiales que revisita: El Libro de Buen Amor, La 
Celestina, La lozana andaluza, San Juan de La Cruz, las Soledades de Góngora y, por supuesto, el Quijote. El canon personal goytisoliano confunde la categoría de autor y la de obra: La Celestina y San Juan, El Libro de Buen Amor y sólo las Soledades de Góngora, el Quijote pero no toda la obra de Cervantes. Las razones de esta selección se fundan en la necesidad de que ser escritor es también un modo de establecer diálogos con el lector. En esa declaración de principios, la poética combativa de Goytisolo se desvanece ante la muestra de una necesidad y un de-seo, escribir para ser leído, con la demostración de una profunda confianza en que la literatura puede modificar radicalmente una escritura pero también una vida.

En 1993, Goytisolo vuelve a exponer su propuesta escrituraria entendida en términos de un aprendizaje y un contagio, marca que sugiere ciertas derivaciones para ver el modo en que los textos provocan su condición de ejemplares, su posibilidad de enseñar y ser enseñados. Ante el avance del inminente fin de siglo, Goytisolo propone volver a la lectura del Quijote en tanto arma contra la tiranía del racionalismo. Pero su apuesta nos advierte de un afán por colocar el texto en tanto portador de un sentido que podríamos llamar didáctico, categoría que Goytisolo soslaya:

¡Ojalá alcanzaran mis obras a contagiar a alguno de ustedes como las de los autores que admiro me han contagiado a mí! ¿A qué cosa mejor podría aspirar un autor-relector como yo que a esta pequeña pero conmovedora recompensa? (Goytisolo, 1993 [1995], p. 214)

Es extraño recuperar en el vocabulario de un crítico disidente, las marcas de la lectura como contagio y la conmovedora operación que la lectura sostiene, gestos que tal vez encuentren su justificación en otra dimensión de análisis.

\section{Saer: la lectura difícil}

Es posible advertir también en la lectura que Juan José Saer realiza del Quijote una necesidad por diferenciarse de lo hecho, ese borramiento de un decir crítico que permite el advenimiento de la novedad, de la lectura propia. Saer funda su lectura del Quijote en el reconocimiento de algunos grandes problemas que la escritura del libro desarrolla. El desmantelamiento de la epopeya, el tema de la lectura como transfiguración del mundo y transformación de la persona y las complejas relaciones entre ficción y realidad. En este último punto, Saer hipotetiza acerca de la fundación por parte del Quijote de la tradición simbólica, del pacto a través del cual podemos volver a creer en la ficción, única condición de cualquier lectura:

Don Quijote, como todos nosotros, salió a los caminos tratando de escapar, no al canto hechicero y prometedor, sino al silencio de las sirenas. También nosotros quisiéramos encontrar algo que vaya más allá de ese silencio, pero es evidente que hemos olvidado, quizá para siempre, la capacidad de forjar el pacto simbólico que nos permita romper ese silencio que es universal, aunque algunos, con el pretexto de haber oído el canto, que en verdad ya sólo es leyenda, hagan de ese supuesto conocimiento la justificación, inverificable desde todo punto de vista, de su intento de dominio. De ahora en adelante, por lo que duren el mar, el aire y las estrellas, seguiremos viviendo en el silencio de las sirenas, debatiéndonos en la realidad material bruta, y chapaleando en el pantano de lo empírico. Nuestra única lucidez posible consiste en reconocer que, como el personaje de Kafka, simbólicamente hemos perdido. En cambio, Don Quijote, él, ganó. (Saer, 1999, pp. 53-54)

Esta batalla ganada en lo simbólico tiene que ver para Saer con otro de los te- 
mas que el libro explicita, el tópico del avance o la progresión difícil. Así como don Quijote avanza lentamente y a diferencia de los héroes épicos, el lector también puede aspirar a un plus de sentido que el texto puede darle si se acepta el desafío de la conmoción. Esta dimensión de la dificultad se relaciona con una categoría que la didáctica de la literatura retoma insistentemente a partir de la formulación de Harold Bloom (2000) acerca de que la lectura es ante todo la búsqueda de un placer difícil. Este cruce entre escritura y lectura puede plantearse si recuperamos el espacio del corrimiento que Saer produce en sus argumentaciones, movimientos que ponen al Quijote más cerca de una enseñanza y más lejos de los ritos de la lectura.

\section{Federico Jeanmaire: escribir la lectura}

El recorrido crítico de Federico Jeanmaire (2004) parece no tener desvíos en relación con un plan perfectamente trazado. En la estela de Goytisolo, Jeanmaire parece decir que porque ha leído puede escribir, especie de lección inaugural de un modo de escribir crítica más cercano a Barthes que a los autores que fundaron el campo del hispanismo. Jeanmaire cuenta una lectura, escribe su manera de leer y la particulariza, su lectura es "una lectura" del Quijote.

La pregunta que el texto de Jeanmaire genera es si ese modo de leer comporta además una propuesta generalizable, si es posible encontrar una metodología que pueda operar en la entrada a cualquier texto. La propuesta es muy clara en este punto al advertir acerca de la excepcionalidad del texto cervantino. Sólo el Quijote permite esa razón de la lectura crítica, fundada en la dificultad, sólo temporal, que conlleva su lectura. Por este motivo, Jeanmaire define su trabajo como un intento por facilitar un poco más el trabajo del lector.

Esta confianza tiene que ver también con las marcas que venimos describiendo. ¿De dónde proviene ese modo de leer? ¿Qué o quién lo posibilita? La respuesta está también en el cruce con el reconocimiento de la dimensión didáctica que el texto arrastra, que no tiene que ver con el modelo medieval sino con el hecho de que el Quijote no enseña a leer, sino a escribir esa lectura, incluida la dificultad. Al ser un libro sobre los libros, el Quijote funda también la escritura crítica en la modernidad en la sucesión de lecturas, continuidad que se interrumpe con el lector, pero que el texto conduce sin vacilaciones:

El Primer Quijote se escribe en contra de la lectura vulgar de los libros de caballerías, de la lectura como verdad de esas ficciones, y los personajes que en lo sucesivo lo irán habitando, se ocuparán de escribir, constantemente, sus muy particulares lecturas de los mismos. El Primer Quijote, entonces, será un libro que habla de otros libros. Pero no lo hará de cualquier modo. No. Lo hará en el mismo sentido en que lo hace el prólogo. A través de la voz de sus personajes y no a través de la voz de los narradores. Lo cual implica una absoluta modernidad pedagógica: las voces contarán sus lecturas, chocarán entre ellas, discutirán o callarán, pero no habrá una postura autoritaria de parte de los narradores o del autor; el lector, libremente, será quien deberá tomar partido, a cada instante, por unas o por otras. Solo, el lector. Librado a su suerte. (Jeanmaire, 2004, pp. 16-17)

De este modo, Jeanmaire evalúa la excepcionalidad del texto cervantino en la recuperación de las condiciones que una didáctica de la lectura puede ofrecer. Lo que el autor argentino llama modernidad pedagógica permite trazar las coordenadas de un deseo que no siempre advertimos los que enseñamos, eso que puede 
intuirse más allá del festivo choque de voces y silencios. Sólo que Jeanmaire no lo aprendió sólo de Cervantes y allí está la clave de su texto.

\section{Ricardo Piglia: las últimas lecciones}

También Ricardo Piglia (2005) intenta abordar la escritura de una lectura o el modo en que puede reconstruirse una posición de lectura. En El último lector, Piglia busca una serie de ejemplos que le permitan rastrear el modo en que está representada la figura del lector en la literatura:

Buscamos, entonces, las figuraciones del lector en la literatura; esto es, las representaciones imaginarias del arte de leer en la ficción. Intentamos una historia imaginaria de los lectores y no una historia de la lectura. No nos preguntaremos tanto qué es leer, sino quién es el que lee (dónde está leyendo, para qué, en qué condiciones, cuál es su historia). Llamaría a este tipo de representación una lección de lectura, si se me permite variar el título del texto clásico de Lévi-Strauss e imaginar la posición del antropólogo que recibe la descripción de un informante sobre una cultura que desconoce. Esas escenas serían, entonces, como pequeños informes del estado de una sociedad imaginaria -la sociedad de los lectores- que siempre parece a punto de entrar en extinción o cuya extinción, en todo caso, se anuncia desde siempre. (Piglia, 2005, pp. 24-25)

Las escenas que Piglia recupera pertenecen a textos de diversa índole como Una excursión a los indios ranqueles, Hamlet, Anna Karenina, cartas de Kafka, textos de Poe, diarios del Che, el Ulises. El Quijote no ocupa ningún capítulo en particular, sólo es recuperado para potenciar los argumentos que el resto de los textos genera en la lectura. Creemos advertir en esta posición una cierta marca de la escritura de la crítica en Argentina para quien la literatura española es sólo ejemplo del ejemplo. Los textos objeto de análisis pertenecen al campo argentino o latinoamericano, pero siempre hay espacio para que el Quijote ejemplifique los modos de la ficción o El Conde Lucanor brinde las claves de la narración fragmentada, pero siempre desde el margen, el borde que ilumina pero que no puede ser explicado ${ }^{2}$. Piglia admite y refuerza esta posición cuando se refiere al Quijote en su texto al reconocer que no vuelve a él por la sencilla razón de que las escenas que busca son escasas en el texto. En efecto, Piglia nos hace notar que a pesar de ser un libro sobre los libros y la lectura, don Quijote no ostenta su caudal libresco. El lector sabe desde el capítulo VI de la primera parte que los libros de Quijano son muchos, "entraron dentro todos, y la ama con ellos, y hallaron más de cien cuerpos de libros grandes, muy bien encuadernados, y otros pequeños” (I, 5, p. 58$)^{3}$, pero sólo lo vemos leer una vez:

En toda la novela nunca vemos a don Quijote leer libros de caballería (salvo en la breve y maravillosa escena en la que hojea el falso Quijote de Avellaneda donde se cuentan las aventuras que él nunca ha vivido. II, 59). Ya ha leído todo y vive lo que ha leído y en un punto se ha convertido en el último lector del género. Hay un anacronismo esencial en don Quijote que define su modo de leer. $Y$ a la vez su vida surge de la distorsión de esa lectura. Es el que llega tarde, el último caballero andante. (Piglia, 2005, p. 189)

Vemos entonces cómo en el final de su texto, Piglia encuentra al que ha estado en los bordes, el que ha podido enhebrar los argumentos que los textos que se analizan en los diversos capítulos no pueden sostener. No olvidemos que ha buscado en esas escenas una lección de lectura, enunciado que conlleva la especificación por una enseñanza que la crítica insistió en dejar en los márgenes pero que no puede silenciarse. 
El Quijote como texto para ser enseñado, el Quijote como texto que enseña, el Quijote como texto que desborda el espacio del ejemplo y permite que la crítica ingrese en los espacios de la confrontación. El contagio con el que Goytisolo se refiere a la escritura, la dificultad en la lectura que Saer reconoce, la modernidad pedagógica de Jeanmaire, las lecciones de lectura de Piglia, son la constatación de una práctica sostenida.

Entre las dimensiones centrales que permitieron configurar el campo de la didáctica de la literatura en nuestro país se encuentra la tesis de Jorge Panesi (2000) acerca de la imposibilidad de enseñar literatura, práctica que sólo se fundaría en lo que Panesi llama una hipótesis del fervor que llama al entusiasmo y que puede compartirse.

Este compartir tal vez tenga que ver con el modo en que la crítica y sus autores reconocen una deuda difícil, aquella que va más allá de la conmoción producida por un texto y que vuelve sobre un hacer cuestionado. En la dedicatoria del libro de Federico Jeanmaire leemos: "A Melchora Romanos, por su facilidad para contagiar la pasión”. En esa breve declaración hay una clave, la que nos dice que el Quijote nos enseñó a leer la dificultad y que los maestros supieron convertirla en lecciones de entusiasmo.

\section{Bibliografía}

Bloom, H.: (2000) Cómo leer y por qué, Norma, Bogotá.

Cervantes SaAvedra, M. DE: El ingenioso hidalgo Don Quijote de La Mancha, edición y notas de Sabor de Cortázar, C. y Lerner, I., Eudeba, 2005, Buenos Aires.

Chiani, M.: (2005) "Hugo Cowes, devoto esencialmente de Borges, que engendró a Pierre Menard, que engendró a Don Quijote" en Olivar 6, Revista de Literatura y Cultura Española, Dunken, La Plata, pp. 75-89. Goytisolo, J.: (1991) "El ceremonial del vacío" en El bosque de las letras, Alfaguara, 1995, Madrid, pp. 245-254.

(1993) "Lectura y relectura", ob cit., pp. 205-215.

Jeanmaire, F.: (2004) Una lectura del Quijote, Seix Barral, Buenos Aires. 
Kundera, M.: (1987) "La desprestigiada herencia de Cervantes" en $E l$ arte de la novela, Tusquets, Barcelona, pp. 13-30.

Panesi, J.: (2000) "Enrique Pezzoni: profesor de literatura" en Críticas, Norma, Buenos Aires.

Piglia, R.: (2005) El último lector, Anagrama, Barcelona.

SAER, J.J.: (1999) "Líneas del Quijote" en La narración-objeto, Seix Barral, Buenos Aires, pp. 33-54.

VILA, J.D.: (2005) "La forja del cervantismo argentino: escuelas, maestros y discípulos de una pasión nacional” en Olivar 6, Revista de Literatura y Cultura Española, Dunken, La Plata, pp. 15-20. 